This item was submitted to Loughborough's Research Repository by the author.

Items in Figshare are protected by copyright, with all rights reserved, unless otherwise indicated.

\title{
Situation Awareness: its proficiency amongst older and younger drivers, and its usefulness for perceiving hazards.
}

\section{PLEASE CITE THE PUBLISHED VERSION}

http://dx.doi.org/10.1016/j.trf.2016.04.011

\section{PUBLISHER}

(c) Elsevier

\section{VERSION}

AM (Accepted Manuscript)

\section{PUBLISHER STATEMENT}

This work is made available according to the conditions of the Creative Commons Attribution-NonCommercialNoDerivatives 4.0 International (CC BY-NC-ND 4.0) licence. Full details of this licence are available at: https://creativecommons.org/licenses/by-nc-nd/4.0/

\section{LICENCE}

CC BY-NC-ND 4.0

\section{REPOSITORY RECORD}

Key, C.E. James, Andrew Morris, and Neil J. Mansfield. 2016. "Situation Awareness: Its Proficiency Amongst Older and Younger Drivers, and Its Usefulness for Perceiving Hazards.". Loughborough University. https://hdl.handle.net/2134/21536. 


\title{
Situation Awareness: its proficiency amongst older and younger drivers, and its usefulness for perceiving hazards.
}

\section{Highlights}

- Older drivers matched younger drivers in Situation Awareness scoring.

- The Situation Awareness scores of younger drivers were significantly related to their scores for hazard perception.

- Younger drivers outperformed older drivers on a hazard perception task, particularly in regards to the speed of detecting a hazard.

- Participants found it significantly easier to demonstrate Situation Awareness when watching video footage of a car journey rather than when actually driving.

- Textual analysis of driver commentaries showed that older drivers were less aware of what was behind their vehicles.

\begin{abstract}
The two studies reported here sought to measure and compare the Situation Awareness (SA) of younger and older driver groups whilst driving (Study 1), and watching video footage of actual car journeys (Study 2). In both studies this was achieved by recording a participant's commentary on what s/he felt was of relevance to the driving task. The narratives produced were analysed by computer software that could abstract main concepts and calculate scores indicative of Situation Awareness. In Study 2, these scores were related to others for hazard perception proficiency (also derived from participant commentaries). It was found that the older drivers matched and often exceeded the younger drivers when their SA scores were compared individually, but not when assessed as a group. However, the younger drivers outperformed their older counterparts in hazard perception ability, and this was shown to be related to their Situation Awareness score. When the results from participants who undertook both studies were compared, it was found that Situation Awareness performance was significantly higher when commenting on video footage (Study 2) than whilst actually driving (Study 1).
\end{abstract}

\section{Keywords}

Situation Awareness; Hazard Perception; Older drivers; 'Think Aloud' method.

\section{Introduction}

1.1. Rising older driver population 
With continuing advances in health and medicine, people are generally living longer. In the UK it is estimated that by the year 2031 almost $23 \%$ of the population will be over 60 (Office for National Statistics, 2010). As the population has aged, so the number of older drivers has risen. Around $52 \%$ of those aged 70 and over currently hold a driving licence (Box, Gandolfi, \& Mitchell, 2010), and the expectation is that the number of drivers in this age group will rise faster than any other (e.g. Burkhardt \& McGavock, 1999; Lyman, Ferguson, Braver, \& Williams, 2002; Box, Gandolfi, \& Mitchell, 2010).

\subsection{Age and driving}

This increase in older drivers has also been matched, albeit to a lesser degree, by other age groups, fomenting predictions that road traffic accidents will be the sixth most prevalent cause of global deaths by the year 2020 (Jacobs, Aeron-Thomas, \& Astrop, 2000). This has led to concerns with regards to older drivers for three principal reasons:

a) There are a range of age-related physiological, perceptual, and cognitive declines (e.g. Laux, 1995; Salthouse, 1985; Smith \& Earles, 1996; Damos \& Wickens, 1980; Korteling, 1993; Lorsbach \& Simpson, 1988; McDowd \& Craik, 1988; Schneider \& Fisk, 1982; Tun \& Wingfield, 1997) that may negatively affect their driving performance, and therefore road safety. Examples include slower motor responses (Rinalducci, Smither, \& Bowers, 1993) and poorer judgement of gaps (Darzentas, McDowell, \& Cooper, 1980).

b) Police reports and insurance data show older drivers are more likely to be considered responsible for the accidents in which they are involved (Langford, Koppel, Andrea, \& Fildes, 2006), and that they tend to involve multiple vehicles and more serious injuries (Morris et al, 2003, Department for Transport, 2004).

c) Older individuals are more likely to suffer serious injury and are at more frequent risk of being fatally injured as a result of an accident - in the region of 2-5 times more than that of a younger person - due to their physical frailty (Department for Transport, 2004). They are also likely to take far longer to recover from their injuries, in comparison to younger accident victims (see Platts-Mills et al, 2015).

\subsection{Situation Awareness and driving}

Situation Awareness (SA) which most often has been defined as "the perception of elements in the environment within a volume of time and space, the comprehension of their meaning, and the projection of their status in the near future" (Endsley, 1988, p97) has relevance for driving safely. It enables us to explain how drivers can combine long-term goals (such as reaching a 
destination), with short-term goals (such as slowing down for a junction) as they drive (e.g. Sukthankar, 1997). To achieve SA, a driver is said to employ a range of cognitive processes, including perception and pattern recognition (Kass et al., 1991), attention and comprehension (Kass et al., 2007; Wickens \& Hollands, 2000), and decision-making (Endsley, 1995b; Ma \& Kaber, 2005). These processes are about conscious recognition and comprehension of a meaningful event (e.g. a roundabout is approaching, so traffic may appear from the right (in the $\mathrm{UK})$ ). And as the number of these events increase, how such information excesses are dealt with will much depend on how attention is distributed: both within tasks (e.g., when a driver determines what to concentrate on); and across tasks (e.g., when s/he divides attention among multiple tasks, such as interacting with in-car technologies).

As such, a lack of, or inadequate levels, of Situation Awareness are said to constitute a primary factor in accidents attributed to human error (Hartel, Smith, \& Prince, 1991; Merket, Bergondy, \& Cuevas-Mesa, 1997; Nullmeyer, Stella, Montijo, \& Harden, 2005). Indeed, Gugerty (1998) points out that "errors in maintaining situation awareness are the most frequent cause of errors in real-time tasks such as driving" (p. 498) and that poor SA can be attributed to more accidents than improper speed or technique.

\subsection{SA and older drivers}

In view of the perceived onerous nature of information processing that is essential to good Situation Awareness, unsurprisingly perhaps, the performance of older drivers has become increasingly scrutinised due, as noted above, to the rapid expansion of this driver group, and growing awareness of age-related cognitive, perceptual and physical declines.

SA researchers have sought to assess how ageing impacts on a driver's ability to attend to important information in driving environments of different complexity. Generally it has been found that older drivers demonstrate poorer SA (e.g. Bolstad, 2001; Zhang, Jin, Garner, Mosaly, \& Kaber, 2009; Kaber, Zhang, Jin, Mosaly, \& Garner, 2012). However, there are studies that have found similar (poor) levels amongst young drivers (Bolstad, 1996), changing SA performance according to environment conditions (e.g. rural, urban, hazards: Zhang, Jin, Garner, Mosaly, \& Kaber, 2009), and in Bolstad \& Endesley (1991), no age effects at all.

Situation Awareness is said to develop with driving experience (Lee, Olsen, \& Simons-Morton, 2006; Randel et al., 1996). There are also observed correlations between SA, driving experience, and safer driving (Soliman \& Mathna, 2009), but such associations have not been found specifically for older drivers. Overall, much of the above ambiguity as to the influence of SA on older (and younger) driver performance is due to insufficient research. 
The purpose of the two studies reported here was to firstly confirm whether older drivers do indeed demonstrate poorer SA when assessed against a younger driver group: whilst actually driving (Study 1); and/or when viewing a driven car journey (Study 2). Secondly, to consider SA differences among those participants who undertook both of these studies, and finally, to assess whether SA might be a predictive factor for scoring on a driving proficiency indicator - hazard perception (Study 2).

\subsection{SA and hazard perception}

This measure was chosen for Study 2, firstly as it has been correlated with traffic accident involvement reporting (e.g. Darby et al., 2009; McKenna \& Horswill, 1999; Quimby et al., 1986; Wells et al., 2008). Secondly, that it has been found to decline with age (e.g. Wallis \& Horswill, 2007), and finally, as it potentially has performance linkages to Situation Awareness. This can be demonstrated through its definitions, such as the ability to read the road (Mills et al., 1998) or to anticipate potentially dangerous situations on it - in effect, having situation awareness for hazardous situations involving roadway environments and users (Horswill \& McKenna, 2004).

In fact, Situation Awareness models, such as Endsley's (1995), might be able to provide a basis for distinguishing between drivers with different skill levels, and even, potentially at least, identifying the causes of individual differences in hazard perception. In her three level model, for example, the lower two levels correspond to perception of a current environment and a comprehension of how a current situation has arisen. So drivers who are better able to extract and relate processed information to relevant road safety, would seem better equipped to demonstrate good awareness at the third and highest level in Endsley's model, projection, or in this context, better driving action decisions when confronted with a potential hazard.

The quality of this inter-relation of processed information is assessed in these studies through a quantitative analysis of each individual participant's information network, gathered from their commentaries as to what they consider as relevant whilst actually driving (Study 1), or seen from the driver's perspective on a videotaped journey (Study 2). The potential as to whether a more cohesive information network is prevalent amongst younger than older drivers (Study 1) which may assist the detection of hazards (Study 2) is then explored.

\section{STUDY 1}

\subsection{Objective and hypotheses}

This study sought to assess the Situation Awareness of older and younger drivers by producing a network of key underlying concepts from narratives recorded by each participant driver 
during a car journey. These were then compared at the individual and group level to discover what information was being utilised and how it differed between and within each driver agegroup. It was hypothesized that the SA metric scores of an older participant group would be less than those in any younger-aged grouping, and that different concepts would be focussed on by the two groups.

\subsection{Method}

\subsubsection{Methodological approach}

The most commonly adopted measures of SA to date tend to either freeze and ask for information during 'drives' within simulated driving environments (e.g. SAGAT: Endsley, 1995b), or after a trial has been completed (e.g. SART: Taylor, 1990).

However, for seeking driver information on actual roadways, a more qualitative-based design, outlined below, was considered a better approach to data capture. In the naturalistic driving context of Study 1, the attributes that underpin driver SA are continually observable. They can be reported on by drivers (in the form, say, of knowledge objects) as they draw them from changing, though, familiar driving environments (i.e. in terms of road infrastructure). Thus, by utilising a participant's own vehicle, with no visible and unusual data capture equipment (e.g. cameras), it was felt that such an approach arguably affords the best chance of capturing feedback that the driver normally would exhibit. This method is then extended to Study 2 for comparison purposes, though again it enabled participants to comment on an actual driven journey without interruption.

\subsubsection{Design}

The study required participants to drive their own cars around a pre-defined route on public roadways, and to provide a verbal commentary whilst doing so. These 'Think aloud' commentaries, more formally known as (Concurrent) Verbal Protocol Analyses (VPAs), are useful for eliciting thought processes and knowledge (see Bainbridge, 1990). They have been used as a means of gaining insights into the cognitive aspects of complex behaviours, and often SA proficiency in military and road traffic contexts (e.g. Stanton and Walker et al., 2007; Walker, Stanton, \& Salmon, 2011).

After the commentaries were recorded, they were later transcribed, and then processed through software capable of extracting each individual (or a group of) narrative's main cognitive and physical concepts, and calculating the cohesion between them. The data derived reflected how well a driver related the concepts that s/he believed to be important, and thus 
provided an insight and a measure of his/her Situation Awareness. The approach has previously been utilised e.g. by Salmon, Young, \& Cornelissen (2013), Walker, Salmon, \& Stanton (2011), and Walker, Stanton, \& Chowdhury (2013).

All trials took place in good visibility and at pre-defined times $(9.30 \mathrm{am}, 11.30 \mathrm{am}$, or $2 \mathrm{pm})$ in order to avoid peak traffic conditions and to retain some control over traffic density.

\subsubsection{Route}

[Figure 1]

The test route was 14.9 miles in length (following a short warm-up phase of 1.3 miles) mainly in Leicestershire, but briefly, also in Derbyshire, in the United Kingdom. It comprised of 3.9 miles of motorway (M1); 3.5 miles along major roads (e.g. A6); 2.9 miles along urban roads; 3.4 miles of rural roads; and 1.2 miles within residential roads. The driver therefore encountered all classifications of UK roadways and numerous and differing roundabouts and junctions. The route took on average, 32.3 minutes for an older driver, and 29.7 minutes for a younger driver to complete. It started and ended at Loughborough University (see Figure 1, above).

\subsubsection{Participants}

20 participants undertook the trial (15 male/5 female), allocated to either an older group (8 male/ 2 female; average age: 75.6 ; \pm 14 years) or a younger group ( 7 male $/ 3$ female; average age: $31.1 ; \pm 17$ years).

\subsubsection{Procedure}

Particular emphasis was placed on the fact that control of the vehicle, and the safety of other road users, remained the participants' responsibility at all times, and therefore that they should drive as they normally would do on each roadway. An instruction sheet on how to perform a 'think aloud' protocol (that had also been received by the participant prior to attendance) was re-read, and the researcher again provided examples of the desired form and the content of the commentary. The participant then drove the practice element of the route, and once content, s/he was then directed around its data capture element, where his/her commentaries were recorded.

\subsubsection{Data analysis}

The commentaries that were captured were transcribed verbatim post-trial, and then subjected to analysis by Leximancer software (Smith, 2003) capable of creating semantic networks (i.e. themes, keywords, key concepts, and the relationships between them) unique to each 
participant and/or group. These networks represented the cognitive elements of the driving task through changing journey environments, and thus provided an insight into an individual's or a group's SA within a driving 'system'.

\subsubsection{Network analysis}

The raw quantitative data sets that the Leximancer software provides can be entered into a mathematical program (Agna, via geocities.com) for structural analysis comparisons. Two of the measures that the software can produce are of particular relevance for Situation Awareness: Density - the level of interconnectivity within a network, in the sense of how proficient the linkages are between its concepts; and Diameter -the efficiency of the paths across a network in terms the number on concepts nodes needed to be traversed. The denser a network, and the shorter its diameter, the better the individuals' Situation Awareness is said to be, as this facilitates faster access to relevant information.

\subsection{Results}

\subsubsection{Quantitative data}

2.3.1.1. SA metric scores for the older and younger driver groupings

[Table 1]

The younger driver group as a whole was found to have more linkages within their information networks (i.e. have more Density). The configuration of the two group's networks, in the sense of the length of the pathways through them (their Diameter) was found to be similar (Table 1). When the older drivers were assessed as individuals, however, with their scores averaged to produce a group score, they then were found to have similar SA cohesion to that of the younger group. Independent Sample t-tests showed no statistical difference between the two groups.

\subsubsection{Qualitative data}

\subsubsection{Individual group data}

In terms of the concepts that were important to the two groups, Figure 2 indicates the main ones for each (the darker the background the higher the word count), and the percentage occurrence with other concepts (the darker the background the stronger the connection). The main concepts in bold text denote its uniqueness to a particular group. 
For the older drivers there was a strong focus on what was 'Coming', particularly 'Towards' their vehicles (linked for this group to three major concepts). Additionally, more relevance was given to 'Traffic', what was to the 'Left' 'Hand' 'Side' of the car, and the act of 'Turning'.

[Figure 2]

The younger group, in comparison, paid particular attention to gear changes, as in going 'Down' gear, and also to their 'Speed' as in slowing 'Down'. There were also indications here of a better awareness of what was 'Behind' the vehicle with linkages to the 'Cars' and (unique to this group) the 'See' concept.

\subsubsection{Combined group data}

The Leximancer software has the capability of comparing the texts of two (or more) groups to reveal the most distinguishing concepts for each. In Table 2 below the software has combined the frequency of a concept (based on its word count) with a 'strength' percentage (which reflects the extent it uniquely applies to one group over another) to produce a Prominence score.

[Table 2]

This Table again shows that the younger group's awareness of 'Speed' and (in particular) their need to 'See' what was behind their vehicles, as particularly differentiating factors. For the older group, it was their tendency to look to the 'Left' hand side of their vehicles, and for 'Traffic'ahead or lights.

A further difference between the two group's perspectives could be gained through a network analysis of all of the concepts that were generated by the narratives, not just the main ones compared in Figure 2/Table 2. This is shown in Figure 3 below.

[Figure 3]

This network again highlights the importance of the 'See' (behind) and 'Speed' concepts for the younger group and the 'Left' and 'Traffic' concepts for the older group by their direct link and often their proximity to the relevant group 'folder' nodes. The apparent better awareness of what was behind the vehicle for the younger group was also evident from the inclusion of the 'Mirror' and its relationship to a 'Checking' concept. For the older group 'Turning' - related to 'Left'; and 'Hour' - as in miles per hour, were additional strong differentiating factors. 


\section{STUDY 2}

\subsection{Objectives and hypotheses}

In Study 1 measures related to Situation Awareness of an older driver group were found to be similar to that of a younger group. However, when the main concepts in the narratives were extracted and compared, the older group had shown indications of being less aware of what was happening around their vehicles. Whilst this may not necessarily impact on them driving safely in less cognitively demanding conditions, such as encountered in Study 1, it could when those conditions became more complex.

Study 2 took the same methodological approach as Study 1, but utilised video footage of 'complex' and 'standard' journeys for comparison purposes due to safety concerns. However, this afforded an advantage of being able to contemporaneously take a measure of hazard perception ability to additionally assess whether a participant's SA proficiency was related to the number of hazards s/he detected in a timely manner. To achieve this, participants were assessed on (whether and) how quickly they were aware of potentially dangerous situations in differing driving environments (see 3.2.1.2. below). Such indicators were chosen as they are considered to be related to driver safety (Horswill \& McKenna, 2004), have been used previously to compare the hazard perception performance of older drivers (Horswill et al, 2008), and in SA studies, when encountered, they have been found to improve older driver performance - particularly in rural conditions (Zhang et al., 2009; Kaber et el., 2012).

It was hypothesised that due to age-related perceptual declines, the Hazard Perception scores and the SA metrics for the 'complex' car journey variant, would be more deficient in the older grouping compared to the younger grouping. Given that half of the participants who volunteered for the study also took part in Study 1, a SA comparison was additionally made with those participants' previous scores to assess whether SA proficiency was easier to achieve whilst driving.

\subsection{Method}

\subsubsection{Design}

The study sought to provide a realistic 'driving experience' by using video footage of real (rather than computer-simulated) car journeys. The footage was shown on a P.C. and comprised of two formats. 


\subsubsection{Commentary for SA measurement}

For this first aspect, 'drivers' provided a verbal commentary of what they considered important from the driver's perspective in video footage of two different journeys, and were asked to include safety-related information as they felt appropriate. The first journey $(7 \mathrm{~m} 28 \mathrm{~s})$ had similar urban driving conditions to that in Study 1 (on this occasion along suburban roads in the outskirts of Poole, UK), the second (7m 50s), was more complex (through Bristol City Centre, UK). The recorded commentaries were then transcribed and analysed, as in Study 1, by Leximancer content analysis and Agna mathematical software.

\subsubsection{Commentary for Hazard Perception measurement}

In this second aspect of the study, participants were (later) judged from their commentaries as to their awareness of one or two hazards within each of fifteen one minute videos, and whether they were detected in a timely manner. Each hazard included two elements; the hazard itself (such as a narrow gap between vehicles) and a necessary related action (such as slowing down, or moving to avoid the hazard). Other examples included: pedestrians crossing the road; cyclists encountered at high speed; vehicles emerging from parking bays; meeting oncoming vehicles on narrow roads; and animals wandering onto the road.

The clips that were used were indistinguishable in format from the two, seven minute, journey clips that the participants viewed in the first aspect of the study. They were chosen at random from 221 examples that had been used in the Hazard Perception element of the UK driving test. As with the first part of the Study, participants were asked to give a verbal commentary (for each one) and to include safety-related information, as appropriate.

\subsubsection{Participants}

20 participants undertook the trial (14 male/ 6 female), allocated to either an older group ( 7 male/3 female; average age: $75.5 ; \pm 11$ years) or a younger group ( 7 male $/ 3$ female; average age $25.7 ; \pm 11$ years). 10 of these participants had undertaken Study 1 ( 8 older/ 2 younger).

\subsubsection{Procedure}

Each participant was briefed on how the research would be conducted and its overall aims, and was offered an opportunity to read again a copy of the 'Think Aloud' instruction sheet that was sent to them prior to their attendance. The researcher re-emphasized the need for the participant to think as s/he would normally do whilst driving, but to keep aspects related to safe transit in mind when providing their commentaries. A one-minute trial was then followed by the two seven-minute (SA measurement) journeys, and then the fifteen one-minute journey 
segments which contained either one or two identifiable hazards (as described above). During these data collection phases the aim was for the experimenter to remain silent and to simply monitor the audio capture process.

\subsubsection{Data analysis}

\subsubsection{Network analysis}

The verbal commentaries for the two seven minute journeys were transcribed verbatim posttrial, and then, as with Study 1, subjected to analysis by Leximancer software for semantic network analysis for each participant and group. Structural metrics (Density \& Diameter) were again calculated through Agna software.

\subsubsection{Hazard Perception}

Of the fifteen clips used in the Study, by chance, the first three contained two hazards and the following twelve, one hazard. The more elements a participant spoke about, the higher hazard identification score $\mathrm{s} /$ he (later) obtained. The scoring system was $0.5 \mathrm{pts}$ for detecting the hazard, and 0.5 pts for mentioning the related movement action - or 0.25 pts for each if there were two actions.

In addition, a further point was awarded for mentioning the hazard 'in time', as determined by a highlighted period within a time indicator (only seen by the researcher). If a participant began mentioning the appropriate hazard during this time period, then s/he would additionally be awarded $1 \mathrm{pt}$. If only the relevant movement cue was mentioned in time, then $0.5 \mathrm{pts}$ would be awarded.

\subsection{Results}

\subsubsection{Quantitative data}

\subsubsection{SA scores}

As, partially at least, with Study 1, if SA was evaluated on a group score basis from combining the narratives of the two longer (seven minute) journeys together, then the younger group again produced the better performance. However, if those journeys were evaluated separately, or if each individual SA score was totalled and then averaged per group, then the older participants were found to perform better on all measures, and significantly so $(\mathrm{p}<0.043)$ when the two journeys were combined (Table 3 ).

[Table 3] 
In comparison to Study 1, the older drivers improved their awareness on these video exercises however they were measured. The younger group, which was far different in composition to that which took part in Study 1, also performed better on the video task when the narratives of the two journeys were combined, but poorer when they were assessed separately. Both groups showed little difference in SA scoring for the two video journeys, even though all participants confirmed that both were different in the level of detail.

\subsubsection{Hazard Perception Scores}

In terms of hazard perception, the younger participants out-performed their older counterparts in overall scoring, with around two thirds of that difference being attributable to the older group identifying the hazards outside of the allotted timeframe (Table 4).

[Table 4]

The difference in scoring between the two groups was not significant, however, for any of these three measures by a paired sample t-test.

\subsubsection{Does better SA lead to better Hazard Perception?}

If the SA scores (taken from combining the two journeys) are compared to the overall Hazard Perception (HP) point scores for all twenty participants, then no relationship was found to exist when assessed by paired sampled t-tests (see Table 5).

However, if the speed aspect of the Hazard Perception Task is taken out, then more of a relationship emerges (see Table 5), with higher SA scorers generally being found to detect the most hazards.

For the younger group, however, a statistically significant relationship was found between the SA scores (from a combined analysis of the two video journeys, or the complex journey alone) and the Hazard Perception scores - whether in total $(\mathrm{p}<0.008)$ or if the speed element was removed $(\mathrm{p}<0.005)$.

[Table 5]

3.3.1.4. Is SA easier to achieve whilst driving or when watching a video of a driven journey?

For this aspect of the Study, the video tasks produced significantly better SA scores for those who had undertaken both studies (Table 6) from a measurement through paired sampled ttests. In particular, and contrary to expectation, participants demonstrated better Situation 
Awareness when commenting on a complex journey shown on video, than when driving a straightforward route.

[Table 6]

\subsubsection{Qualitative data}

\subsubsection{Main and related concepts}

In Figure 4, below, the main and related concepts that were important for the two participant groups are recorded with the relevant percentage between each being given. The main concepts in Study 1 that retained their importance for a group in this study are in bold type. As when reporting Study 1, the darker background shading is indicative of a higher word count (for the main concepts) or interrelation (between concepts and a main concept).

Overall, the key concepts were more similar in this study. For the older groups, all eight that were considered important for Study 1 were again represented in Study 2. Their relative importance did change, though, with 'Going' - 'Straight' rising in prominence, as 'Coming' 'Towards' disappeared. The 'Traffic' concept was again evident, but became more related to 'Green' lights than 'Lights' in general in Study 1. The more individual 'Car' concept also fell in its ranked importance, as did its direct relationship to 'Parked' cars, where concern here was more for those parked on the 'Left' ( than on the 'Right' in Study 1). Finally, 'Van'(s) also appeared to have relevance for the older group in this study, but this was not evident in the driving study.

[Figure 4]

The Younger Group, which was less homogenous between the two studies, produced more new main concepts (4) than the older group. However, this appeared to be due to the task. The top ranking concept from Study 1, for example, 'Down' - as in going down gear, is more relevant to driving than merely watching someone drive. This explanation also would account for the disappearance of 'See' - and the related 'Behind' concept, and potentially 'Speed' - as in slowing down speed. These main concepts were replaced by 'Traffic' and a related 'Lights' concept. There was also more apparent awareness of 'Red' signals for this group (in contrast to 'Green' for the older group). Finally, a 'Side' concept became a new main concept inclusion, as it did for the older group, but here there was a particular linkage to 'Parked' cars.

\subsubsection{Combined Group data}


The differences between the narratives given by the older and younger participants were again assessed by the Leximancer software to reveal the most distinguishing main concepts for each group.

As can be seen in Table 7 (below), the most distinguishing main concept for the older group was 'Turning' - as in the act of turning 'Into', or 'Left' and 'Right'. The low frequency of its use within the text (6\%) excludes it as a main group concept (given in Figure 4), but due to its relative 'strength' within the network for the older participants it then emerges as a key distinguishing concept when the two groups are directly compared. Four other concepts: 'Coming', 'Going', 'Right', and 'Left', all of which were main concepts for the older group (Figure 4), also showed some uniqueness, whereas the important 'Traffic' concept had little distinguishing value due to it being mentioned almost as frequently $(12 \%)$ as that of the younger group.

[Table 7]

The younger participants, in contrast, generally produced no outstanding distinguishing concepts for this study. The 'Cars' concept, with a 52\% strength score was calculated as the most unique here, due to its high text frequency (16\%). This gives it a 'Prominence' scoring that matches the top four distinguishing concepts for the older group, though it is not calculated by the software as being as distinctive as the 'Turning' concept.

Finally, Figure 5 again shows the relevance of all the generated concepts for each of the two groups in a network format. Here it can be seen that whereas 'Cars' maybe an important main concept for the younger group, as 'Traffic' or 'Turning' were for the older group (Figure 4/Table 7 , above), neither were as prominent as 'cyclist' for the younger group and 'area' for the older group in Figure 5.

[Figure 5]

\section{Discussion}

\subsection{SA scoring}

In these two studies, if participant narratives are analysed together as a group, then younger groups out-perform older groups. However, if this information is broken down (by journey, as in Study 2, or by the individual, as in both Study $1 \& 2$ ), then older participants can be seen to match and often out-perform their younger counterparts. If SA could be quantified for the older 
driver population, then, it would probably record a lower score than any younger age grouping. However, this would mask the good individual performances found here that suggest a limited relationship between SA proficiency and age (at least to those in their 70's and 80's).

This was particularly evident in Study 2, where it appears that with all relevant information to the front of participants, and with additional driving-related activity now redundant, any advantage afforded to the younger group from their apparently more proficient perceptual activity in Study 1 was no longer relevant. As a consequence, the main concepts given by both age groupings became less distinguishable. And contrary to expectation, the more complex video journey actually produced better Situation Awareness proficiency for the older driver group. Feedback suggested that this might have been due to them finding the task more difficult than actually driving, and therefore having to concentrate more.

However, despite this better awareness, the older driver group, which was far more homogenous, and had more exposure to the 'think aloud' method, still assigned less importance to objects that might potentially cause an accident. A contrast can be made, for example, between 'Vans', that were a distinguishing concept for the older drivers in Figure 4 (though located more towards the younger drivers in Figure 5), against 'Bus', 'Red' (traffic light), and 'Crossing' (a road) for the younger drivers in Figure 4, and in Figure 5, 'pedestrian', 'people', and 'cyclist'. Although 'Cars' were a main concept for both groups, Figure 5 and, particularly, Table 7, show that it too had more relevance for the younger participants.

\subsection{The relative ease of the two studies for achieving proficient SA}

It was found that, in general, actual driving produced more extremity in SA scoring, against more consistent scoring of the video-footage of car journeys. However, when the scores of just the ten participants who took part in both studies were directly compared, then the video tasks produced significantly higher SA scores (Table 6).

This is an important issue for SA and driving research, as it suggests that simulated driving, usually employed by SA studies in the literature, (e.g. Bolstad, 2001; Zhang, Jin, Garner, Mosaly, \& Kaber, 2009; Kaber, Zhang, Jin, Mosaly, \& Garner, 2012) may be a poor substitute for measuring how well a driver actually might perform in his/her own car due, potentially, to insufficient cognitive workload. This contention appears to be further supported by a lack of difference in scoring between the two video tasks, even though both were considered by all participants, after the tasks were concluded, as being different in their complexity.

\subsection{SA and hazard perception}


In terms of SA and hazard perception capability, it appears that SA may be of more relevance for younger rather than older driver performance. It is possible that due to declinations in perceptual processing capabilities with age, some of the older drivers were unable to detect certain hazards, and more often, not within safe reaction times. In contrast, the younger participants, though not having such encumbrances, perhaps indicate the possibility for a general SA to HP relationship as Horswill \& McKenna (2004) suggest. This is shown from the strong statistical correlation between their scores on these two measures - particularly when the speed of detecting a hazard was removed. Those who scored highly for Situation Awareness also scored highly on hazard perception, and thus if a younger driver's SA can be improved, and training has showed that this is possible (Stanton, Walker, Young, Kazi, \& Salmon, 2007; Soliman \& Mathna, 2009; and Walker, 2009), then perhaps this in turn could raise his/her hazard perception ability.

The scoring differences, however, may have been influenced by the speed of the vehicle used in the test, as a majority of the older participants, and some of the younger group, felt that it was driving faster than they would on many of the roadways. In the recordings older drivers are often heard exalting the driver to 'slow down' or, for example, that 'we're going far too fast on this' [stretch of road]. Thus, if the driver in the videos had progressed more slowly, a greater percentage of (particularly) the older group might have been able to identify the required hazard within the prescribed timeframe. This may have implications for the current UK Hazard Perception Test.

\subsection{Limitations}

The 'think aloud' methodology chosen for this study, whilst being less obtrusive and easy for the participants to understand, also impacts on the number who can be assessed within a reasonable time period. This is principally due to the need for commentaries to be accurately transcribed, and then formatted as truly as possibly to a participant's enunciation. Thus with the limited numbers also comes a limit on the extent of text that can be analysed, and therefrom, the generalisations that can be made - though this issue is not uncommon in SA research.

Also, the SA scores found here reflect cohesive processing, not optimal driving-related processing. It is thus important to compare the main concepts given by each individual or group, to gain a sense of what she, he, or the group is seeking to process.

\section{Conclusion}


In Study 2 an older 'driver' group identified fewer hazards, and in a less timely manner, than a young 'driver' group, yet their SA scores in both Study 1 and 2 were found to be as good, if not better. This raises the issue of the relevance of SA for hazard detection amongst older drivers. Being able to demonstrate a good cohesive awareness from a high degree of information processing may not necessarily help detect a hazard, if, for example, too much information is being sought that cannot be processed in a timely fashion, or if information is being processed cohesively, though less rigorously.

Hazard perception may therefore be more about processing depth than cohesive awareness. The younger group in Study 2 exhibited more depth in their processing, despite producing an appreciably lower word count than their older counterparts. This was also (and more) evident in Study 1. In contrast, the older participants appeared to have undertaken a broader processing of, principally, movement cues in both studies. For example in Study 1: 'Coming' 'Towards'; in Study 2, 'Going' 'Straight'. Perhaps this was due to information processing inadequacies, but whatever the reason(s), this approach appeared to have provided a better basis for achieving good Situation Awareness cohesion scores at the individual level, but at the expense of (safetyrelated and rearward) object awareness in Study 1, and perceiving hazards in Study 2.

\section{Acknowledgements}

These studies were made possible by funding from Loughborough University's Design School and Wolfson School of Engineering.

\section{References}

Bainbridge L (1990). Verbal protocol analysis. In J.R. Wilson and E.N. Corlett (Eds.), Evaluation of Human Work. London : Taylor and Francis.

Bolstad CA (2001). Situation awareness: does it change with age. In: Proceedings of the human factors and ergonomics society 45th annual meeting, 8-12 October, Minneapolis, Minnesota.

Bolstad CA (1996), Bolstad CA \& Endsley MR (1991) cited in Endsley MR and Garland DJ (Eds.), Situation Awareness Analysis and Measurement, (pp 277-302). Mahwah, NJ: Lawrence Erlbaum Associates, Inc.

Box E, Gandolfi J, \& Mitchell K (2010). Maintaining safe mobility for the ageing population. - the role of the private car. Royal Automobile Club Foundation Report (April 2010). RAC Foundation.

Burkhardt JE \& McGavock AT (1999). Tomorrow's Older Drivers, Who? How Many?, What Impacts? Transportation Research Record 1693: 62-70. National Research Council, Washington, DC. 
Damos D \& Wickens CD (1980). The acquisition and transfer of time-sharing skills. Acta Psychol., 6: 569-577.

Darby P, Murray W, Raeside R (2009). Applying online fleet driver assessment to help identify, target and reduce occupational road safety risks. Safety Science, 47 (3): 436-442.

Darzentas J, McDowell MRC, \& Cooper D (1980). Minimum acceptable gaps and conflict involvement in a simple crossing manoeuvre. Traffic Engineering and Control, 21 (2), 58-61.

Department for Transport (2004). Older drivers: a literature review. Road Safety Research Report No.25. Department for Transport.

Endsley MR (1988). Situation awareness global assessment technique (SAGAT). Proceedings of the National Aerospace and Electronics Conference (NAECON), 789-795. New York: IEEE. doi:10.1109/NAECON.1988.19509.

Endsley MR (1995a). Towards a theory of situation awareness in dynamic systems. Human Factors, 37: 32-64.

Endsley MR (1995b). Measurement of situation awareness in dynamic systems. Human Factors, 37: 65-84.

Gugerty, L. (1998). Evidence from a partial report task for forgetting in dynamic spatial memory. Human Factors, 40(3): 498-508.

Hartel CEJ, Smith, K, \& Prince C. (1991). Defining aircrew coordination: Searching mishaps for meaning. Paper presented at the 6th International Symposium on Aviation Psychology, Columbus, $\mathrm{OH}$.

Horswill MS, Marrington SA, McCullough CM, Wood J, Pachana NA, McWilliam J, \& Raikos MK (2008). The Hazard Perception Ability of Older Drivers. Journal of Gerontology: Psychological Sciences, 63B(4):212-218.

Horswill MS \& McKenna FP (2004). Drivers' hazard perception ability: Situation awareness on the road. S. Banbury, S. Tremblay (Eds.), A cognitive approach to situation awareness: Theory and Application, Ashgate, Aldershot, UK, pp. 155-175.

Jacobs G, Aeron-Thomas A, \& Astrop A (2000). Estimating Global Road Fatalities. London: Transport Research Laboratory. (TRL Report 445).

Kaber D, Zhang Y, Jin S, Mosaly P, \& Garner M (2012). Effects of hazard exposure and roadway complexity on young and older driver situation awareness and performance. Transportation Research Part F: Traffic Psychology and Behaviour, 15 (5): 600-611.

Kass, SJ, Cole, KS, \& Stanny CJ (2007). Effects of distraction and experience on situation awareness during simulated driving. Transportation Research (Part F), 10: 321-329.

Kass SJ, Herschler, DA, \& Companion MA (1991). Training situational awareness through pattern recognition in a battlefield environment. Military Psychology, 3(2), 105-112.

Korteling JE (1993). Effects of age and task similarity on dual-task performance. Human Factors, 35: 99-114. 
Langford J, Koppel S, Andrea D, \& Fildes B (2006). Determining older driver crash risk responsibility from police and insurance data. Traffic Injury Prevention, 7: 343-351.

Laux L (1995). Aging techniques. In Weimer J (Ed.), Research techniques in human engineering (pp. 143-164). Englewood Cliffs, NJ: Prentice Hall.

Lee SE, Olsen ECB, \& Simons-Morton BG (2006). Eye glance behavior of novice teen and experienced adult drivers. Transportation Research Board Record, 1980: 57-64.

Lorsbach TC \& Simpson GB (1988). Dual-task performance as a function of adult age and task complexity. Psychol. Aging 3: 210-212.

Lyman S, Ferguson S, Braver E, \& Williams A (2002). Older driver involvements in police reported crashes and fatal crashes: trends and projections. Injury Prevention, 8: 116-12.

Ma R \& Kaber DB (2005). Situation awareness and workload in driving while using adaptive cruise control and a cell phone. International Journal of Industrial Ergonomics, 35: 939-953.

McDowd JM \& Craik FIM (1988). Effects of aging and task difficulty on divided attention performance. J Exp. Psychol. Human Percept. Perform. 14: 267-280.

McKenna FP \& Horswill MS (1999). Hazard perception and its relevance for driver licensing. Journal of the International Association of Traffic and Safety Sciences, 23 (1):26-41.

Merket DC, Bergondy M, and H. Cuevas-Mesa. 1997. Making sense out of teamwork errors in complex environments. Paper presented at the 18th Annual Industrial/OrganizationalOrganizational Behavior Graduate Student Conference, March. Roanoke, Virginia.

Mills KL, Hall RD, McDonald M, \& Rolls GWP (1998). The effects of hazard perception training on the development of novice drivers skills. Report to Department of the Environment, Transport and Regions. London, UK.

Morris AP, Welsh R, Frampton R, Charlton J, \& Fildes B (2003). Vehicle crashworthiness and the older motorist. Ageing and Society, 23: 395-409.

Nullmeyer, Stella, Montijo, \& Harden (2005) Nullmeyer, R.T., Stella, D., Montijo, G.A., \& Harden, S.W. (2005). Human factors in Air Force flight mishaps: Implications for change. Proceedings of the 27th Annual Interservice/Industry Training, Simulation, and Education Conference (paper no. 2260). Arlington, VA: National Training Systems Association.

Platts-Mills TF, Flannigan SA, Bortsov, AV, S Smith, Domeier RM, Swor, RA, Hendry PL, Peak DA, Rathlev NK, Jones JS, Lee DC, Keefe FJ, Sloane PD, \& McLean SA (2015). Persistent Pain Among Older Adults Discharged Home From the Emergency Department After Motor Vehicle Crash: A Prospective Cohort Study. Annals of Emergency Medicine (in print).

Quimby AR, Maycock G, Carter ID, Dixon R, \& Wall JG (1986). Perceptual Abilities of Accident Involved Drivers (Research Report 27). Transport and Road Research Laboratory, Crowthorne, UK.

Randel JM, Pugh HL \& Reed SK (1996). Differences in expert and novice situation awareness in naturalistic decision making. International Journal of Human-Computer Studies, 45 (5): 579597. 
Rinalducci EJ, Smither JA-A, \& Bowers C (1993). The effects of age on vehicular control and other technological applications, in Wise JA, Hopkin VD, and Stager P (Eds.), Verification and Validation of Complex Systems: Additional Human Factors Issues, pp 149-166, Daytona Beach, FL: Embry-Riddle Aeronautical University Press.

Salthouse TA (1985). Speed of behavior and its implication for cognition. In: Birren JE, Schaie KW (Eds.) Handbook of the psychology of aging. (pp. 400-426) Reinhold, New York.

Salmon PM, Young KL, \& Cornelissen M (2013). Compatible cognition amongst road users: The compatibility of driver, motorcyclist, and cyclist situation awareness. Safety Science 56:6-17.

Schneider W \& Fisk AD (1982). Concurrent automatic and controlled visual search: can processing occur without costs? J. Exp. Psychol. Learn Mem. Cogn, 8: 261-278.

Smith AD \& Earles JL (1996). Memory changes in normal aging. Blanchard-Fields F, Hess TM, (Eds.) Perspectives on cognitive change in adulthood and aging (pp. 192-220). McGraw-Hill, New York.

Smith AE (2003). Automatic Extraction of Semantic Networks from Text using Leximancer. Paper presented at the HLT-NAACL 2003 Human Language Technology Conference, May - June 2003, Edmonton.

Soliman AM \& Mathna EK (2009). Metacognitive Strategy Training Improves Driving Situation Awareness. Social Behavior and Personality: an International Journal, 37 (9): 1161-1170. Scientific Journal Publishers.

Stanton NA, Walker GH, Young MS, Kazi T \& Salmon PM (2007). Changing drivers' minds: the evaluation of an advanced driver coaching system. Ergonomics, 50 (8): 1209-1234.

Sukthankar R (1997). Situation awareness for tactical driving. Unpublished doctoral dissertation, Carnegie Mellon University, Pittsburgh.

Taylor RM (1990). Situational Awareness Rating Technique (SART): The development of a toll for aircrew systems design. In: AGARD Conference Proceedings No 478, Situational Awareness in Aerospace Operations. Aerospace Medical Panel Symposium, Copenhagen, 2nd -6th October 1989.

Tun PA \& Wingfield A (1997). Language and communication. In: Fisk AD, Rogers WA (Eds.) Handbook of human factors and the older adults (pp. 125-149) Academic, San Diego, CA.

Walker GH (2009). Does advanced driver training improve situation awareness? Applied Ergonomics, 40(4): 678-687.

Walker GH, Stanton NA, \& Chowdhury I (2013). Self Explaining Roads and situation awareness. Safety Science, 56:18-28.

Walker GH, Stanton NA, \& Salmon PM (2011). Cognitive compatibility of motorcyclists and car drivers. Accident Analysis and Prevention, 43 (3): 878-888.

Wallis TSA \& Horswill MS (2007). Using fuzzy signal detection theory to determine why experienced and trained drivers respond faster than novices in a hazard perception test. Accident Analysis and Prevention, 39 (6):1177-1185. 
Wells P, Tong S, Sexton B, Grayson G, \& Jones E (2008). Cohort II: A Study of Learner and New Drivers. Department for Transport, London, UK.

Wickens CD \& Hollands JG (2000). Engineering psychology and human performance (3rd ). Upper Saddle River, NJ: Prentice Hall.

Zhang Y, Jin S, Garner M, Mosaly P, \& Kaber D (2009). The Effects of Aging and Cognitive Stress Disposition on Driver Situation Awareness and Performance in Hazardous Conditions.

Proceedings of the IEA 2009 17th World Congress on Ergonomics, Beijing, China. 